\title{
Critical analysis of surgical difficulties and postoperative morbidities of caesarean deliveries: a rural teaching hospital experiences in silk city, South India
}

\author{
Wills G. Sheela*, M. Chellatamizh, M. Mohanambal
}

Department of Obstetrics and Gynecology, SSSMCRI, Ammapettai, Kancheepuram, Tamil Nadu, India

Received: 06 April 2017

Accepted: 02 May 2017

*Correspondence:

Dr. Wills G. Sheela,

E-mail: drgwillssheelaa@yahoo.in

Copyright: $($ ) the author(s), publisher and licensee Medip Academy. This is an open-access article distributed under the terms of the Creative Commons Attribution Non-Commercial License, which permits unrestricted non-commercial use, distribution, and reproduction in any medium, provided the original work is properly cited.

\begin{abstract}
Background: Caesarean section is the delivery of a fetus through a surgical incision on the uterine wall after 28 weeks of gestation. Objectives of present study were to determine the caesarean section rate, to analyse surgical difficulties and post-operative morbidites in caesarean deliveries and to formulate modalities to reduce morbidity and to ensure safe motherhood.

Methods: Retrospective analysis of caesarean deliveries in Shri Sathya Sai Medical College and Research Institute, Ammapettai from January 2015-2017. Total number of delivery in these two year were 494.Total vaginal delivery210, Total caesarean delivery-284. Case records of women who had cesarean deliveries were analysed for intra operative complications and post-operative morbidity within the period of their hospital stay.

Results: Total no of deliveries in 2 years were 494 . Vaginal delivery was $210(42.5 \%)$. Total caesarean section is $57.5 \%(n=284)$. Primary caesarean section rate $33.1 \%(n=94)$ and secondary cesarean section rate $66.9 \%(n=190)$. $60 \%$ of our subjects were un-booked emergency admissions. Majority were between 21-30 years. Youngest is 16yr old with imminent eclampsia, oldest $35 \mathrm{yr}$ with previous 3 LSCS with central placenta previa. Non-closure of peritoneum in previous caesarean has increased the risk of adhesions, plastered rectus muscle and bladder adhesion which caused difficulty in reaching lower segment in 62 women. In present study, vertical incision was put on uterus in 4 cases due to adhesions. Difficulty in entering uterine cavity, extension of uterine angle due to thick lower segment and excessive bleeding was seen in cases of repeat caesarean section. Scar dehiscence has increased due to single layer closure of uterus. Scar dehiscence was noted in 41 cases. Bladder injury in 3 cases, adherent placenta over the scar was seen in 5 cases.

Conclusions: Caesarean section rate is increasing. Intraoperative complications and postoperative morbidity is comparatively less in primary caesarean section. More than one morbidity was seen in $60 \%$ women who had repeat section. With the growing rate of cesarean deliveries worldwide, women should be counselled that the repeat cesarean are bound with surgical difficulties and complications. If available, it's imperative to take the senior obstetricians help for better surgical outcome. Anticipation of complications, early decision and active intervention reduces morbidity and prevent mortality as most of the women report for admissions late in labour.
\end{abstract}

Keywords: Bladder injury, Dense adhesions, Postpartum hemorrhage, Scar dehiscence 


\section{INTRODUCTION}

Caesarean section is the delivery of a fetus through a surgical incision on the uterine wall after 28 weeks of gestation. ${ }^{1}$ The origin of the term caesarean section is obscure but several different theories are promulgated. ${ }^{2,3}$ Historians agree that the term caesarean section has nothing to do with the birth of Julius Caesar. ${ }^{2,3}$ The term probably was derived from 'Lex Caesarea' a decree in the Roman law (715 672 B.C) requiring that before burial of any woman dying in late pregnancy, the child be removed from the uterus. ${ }^{3}$ The term probably derives from the Latin verb caedere meaning to cut. ${ }^{3}$

First documented operation on living women was in 1600. She died on the $25^{\text {th }}$ post-operative day due to infection from open uterus and abdominal wounds. ${ }^{2}$ First successful caesarean was done in USA in $1794 .^{2}$ In early caesarean section, no sutures were placed in the uterus, and caesarean deliveries were associated with $100 \%$ maternal mortality, mostly due to infection or haemorrhage. ${ }^{3}$ The first major surgical advance in the technique was introduced by Porro, in which the uterine fundus was amputated following the delivery of the fetus and placenta, And the cervical stump marsupialized to the anterior abdominal wall. ${ }^{3}$

Scanger M advocated performing a vertical incision on the uterus avoiding the lower uterine segment and recommended closing the uterus in two layers, using silver wire for the deep suture and fine silk for the superficial serosa. ${ }^{3}$ Kronig recommended transperitoneal vertical incision in the lower uterine segment. ${ }^{3}$ Kerr M recommended semilunar transverse lower uterine segment incision with the curve pointing upward. This uterine incision is still used today.

With the subsequent development of antibiotic therapy and modern bloodbanking techniques, caesarean section has evolved into one of the safest and most commonly performed major operative procedures. ${ }^{3}$ Caesarean section has contributed immensely to improve obstetric care throughout the world. ${ }^{4}$ Like any other major abdominal surgery; caesarean section is not free of complication. These complications are major contributors to maternal morbidity and mortality. ${ }^{5,6}$ The caesarean section rate vary widely both within and between countries. ${ }^{4}$

\section{METHODS}

Retrospective analysis of caesarean deliveries in Shri Sathya Sai Medical College and Research Institute, Ammapettai from January 2015-2017. Total number of delivery in these two year were 494.Total vaginal delivery-210, Total caesarean delivery-284. Case records of women who had cesarean deliveries were analysed for intra operative complications and post-operative morbidity within the period of their hospital stay.

\section{RESULTS}

Table 1 shows total delivery statistics for 2 years. Total no of deliveries in 2 years were 494 . Vaginal delivery was $210(42.5 \%)$. Total caesarean section was 284 (57.5\%). Primary caesarean section rate was $33.1 \%$ $(n=94)$ and secondary cesarean section rate was $66.9 \%$ $(\mathrm{n}=190)$. In present study incidence of caesarean delivery was $57.5 \%$. Elective primary LSCS was done in 45 cases, emergency primary section in 49 cases. Elective repeat section was done in 80 cases, emergency repeat section in 110 cases. $60 \%$ of present subjects were un-booked emergency admissions.

Table 1: Delivery statistics for 2 years.

\begin{tabular}{|lll|}
\hline & N & $\%$ \\
\hline Total no of deliveries & 494 & \\
\hline Labour naturalis & 210 & 42.5 \\
\hline Total caesarean & 284 & 57.5 \\
\hline Primary LSCS & 94 & 33.1 \\
\hline Elective & 45 & 47.8 \\
\hline Emergency & 49 & 52.2 \\
\hline Secondary LSCS & 190 & 66.9 \\
\hline Elective & 80 & 42.1 \\
\hline Emergency & 110 & 57.8 \\
\hline
\end{tabular}

Table 2 shows age group of patients who underwent caesarean section. Majority were between 21-30 years.67\% women who had primary caesarean section were in the age group (21-30 years). 68.9\% women who had secondary section were in the same age group.

There is no significant difference between two groups with respect to their age. Youngest was 16 years old primi gravida with imminent eclampsia and uncontrolled hypertension and eldest was 35 years old previous 3 caesarean with central placenta previa.

Table 2: Age group.

\begin{tabular}{|ll|l|}
\hline Age & $\begin{array}{l}\text { Primary LSCS } \\
(\mathrm{n}, \%)\end{array}$ & $\begin{array}{l}\text { Repeat LSCS } \\
(\mathrm{n}, \%)\end{array}$ \\
\hline Less than 20 & $12(12.7)$ & $15(7.8)$ \\
\hline $21-30$ & $63(67)$ & $129(68.9)$ \\
\hline $31-35$ & $19(20.3)$ & $46(24.3)$ \\
\hline Total & 94 & 190 \\
\hline
\end{tabular}

Table 3 shows parity of women who had CS. Majority of patients were second gravid-166 (58.4\%).

Table 2: Parity.

\begin{tabular}{|lll|}
\hline Gravida & No. of patients & $\%$ \\
\hline Primi & 94 & 33.3 \\
\hline Second gravida & 166 & 58.4 \\
\hline Third gravida & 21 & 7.3 \\
\hline Fourth gravida & 3 & 1 \\
\hline
\end{tabular}


Table 4: Difficulty in entering abdominal cavity and lower uterine segment.

\begin{tabular}{|c|c|}
\hline Cicatrisation of abdominal scar & 16 \\
\hline $\begin{array}{l}\text { Ventri fixation of anterior surface of uterus } \\
\text { (plastered uterus) }\end{array}$ & 42 \\
\hline \multicolumn{2}{|l|}{ Adhesions } \\
\hline Flimsy & 106 \\
\hline Dense & 44 \\
\hline \multicolumn{2}{|l|}{ Adherent to uterine surface } \\
\hline Bladder & 26 \\
\hline Rectus muscle & 13 \\
\hline Placenta & 5 \\
\hline Thick lower segment & 62 \\
\hline
\end{tabular}

Table 4 shows causes for difficulty in entering abdominal cavity. There was no difficulty in 100 cases out of 284 caesareans. More than one morbidity is seen in 87 cases. Out of 80 women who had RPM Scar 42 had dense adhesions binding anterior abdominal wall with uterus, rectus muscle was adherent to uterine surface in 13 cases, bladder was adherent to uterus in 26 cases and adherent placenta was seen in 5 cases. There was difficulty in reaching lower segment in 62 cases. Vertical incision was put on uterine surfaces in 4 cases.

Table 5: Intraoperative complications in primary caesarean section $(\mathrm{N}=94)$.

\begin{tabular}{|lll|}
\hline Thick lower segment & N & $\%$ \\
\hline Increased bleeding & 56 & 59.5 \\
\hline Difficulty in delivery of head & 39 & 41.4 \\
\hline Extension of uterine wound & 26 & 27.6 \\
\hline $\begin{array}{l}\text { Broad ligament hematoma with } \\
\text { uterine artery injury }\end{array}$ & 13 & 13.8 \\
\hline Atonic PPH & 3 & 3.2 \\
\hline Increased surgery time & 3 & 3.2 \\
\hline
\end{tabular}

Table 5 shows intra operative complications in primary caesarean. 94 had primary caesarean sections. There was difficulty in opening the uterine cavity due to thick lower segment in 56 cases, prolonged surgery time in 48 cases, excessive bleeding in 39 cases, difficulty in delivering the head in 26 cases, extension of uterine angle in 13 cases and broad ligament hematoma in 3 , atonic $\mathrm{PPH}$ in 3 cases.

Table 6 shows Intra operative complications in repeat caesarean section. Extension of uterine angle seen in 21 subjects, uterine artery injury with broad ligament hematoma in 6 , injury to bladder in 3 cases. Adherent placenta was seen in 5 of our cases. Piece meal removal of adherent placenta with hemorrhage in 1 case (managed by leaving insitu and postop methotrexate injection). Atonic PPH was seen in 36 cases, excessive bleeding (apart from atonicity) was seen in 60 cases, increased surgery time in 91 case. Scar dehiscence was noted in 41 cases, ruputured uterus was present in 1 case which was managed successfully by approximation and avoiding hysterectomy.

Table 6: Intra operative complications in secondary caeserean section $(\mathrm{N}=190)$.

\begin{tabular}{|lll|}
\hline Extension of uterine incision & N & $\%$ \\
\hline $\begin{array}{l}\text { Uterine artery injury with broad } \\
\text { ligament hematoma }\end{array}$ & 21 & 11.05 \\
\hline Scar dehiscence & 6 & 3.15 \\
\hline Rupture uterus & 41 & 21.5 \\
\hline $\begin{array}{l}\text { Piece meal removal of adherent } \\
\text { placenta with hemorrhage }\end{array}$ & 1 & 0.52 \\
\hline Adherent placenta & 1 & 0.52 \\
\hline Atonic PPH & 5 & 2.63 \\
\hline Bladder injury & 36 & 18.9 \\
\hline Excessive bleeding apart from atonicity & 3 & 1.57 \\
\hline Increased surgical time & 91 & 31.5 \\
\hline
\end{tabular}

Table 7 shows Post-operative morbidity. Morbidity within their stay in hospital were analysed. Average hospital stay was 8 days. $73.9 \%$ had postoperative morbidity. Most common morbidity was fever.75 cases had fever, 43 due to urinary E. coli infection and 32 due to wound infection. Second common morbidity was anaemia, with hemoglobin less than $7 \mathrm{gm}$. 62 subjects who were anemic needed blood transfusion. Resuturing of abdominal wound was done in 26 cases. Secondary hemorrhage was seen in 18 women due to sepsis. Paralytic ileus was seen in 6 women. Relaparatomy was done in one case for severe intra-abdominal bleeding.

Table 7: Postoperative morbidity.

\begin{tabular}{|lll|}
\hline & N & $\%$ \\
\hline Fever & 75 & 26.4 \\
\hline UTI due to E. coli & 43 & \\
\hline Wound infection & 32 & \\
\hline Anemia & 62 & 21.8 \\
\hline Resuturing of wound & 26 & 9.15 \\
\hline Secondary hemorrhage & 18 & 6.3 \\
\hline Paralytic ileus & 6 & 2.1 \\
\hline Relaparotomy & 1 & 0.35 \\
\hline Total & 210 & 73.9 \\
\hline
\end{tabular}

\section{DISCUSSION}

Caesarean section is the most common obstetric operative procedure worldwide. The incidence of c-section is continuously increasing for the last couple of decades giving women frequently an obstetric status of previous cesarean section. While the crucial, lifesaving role of cesarean section (CS) in modern obstetrics is obvious, the potential adverse impact of high CS rates is less expressed about raising CS rates and their potential complications especially during a repeat cesarean section in many countries. ${ }^{7,11}$ 
In present study, caesarean section rate is $57.5 \%$. $60 \%$ of our subjects were un-booked emergency admissions. This rate is high when compared to Garba NA, their caesarean rate was $15.8 \%$ and $33.5 \%$ were booked elsewhere and $20.2 \%$ were unbooked. ${ }^{8}$

Higher rates of maternal morbidity were found for nearly all age groups. No significant correlation with age of the patient and complication of caesarean section. Majority of women were second gravida. Women who had no previous caesarean had lower rates of morbidity compared to women who had previous caesarean delivery. These observations are similar to Curtin SC, Munshi SP. ${ }^{9,10}$

Surgical difficulties like cicatrized abdominal scar, difficulty in opening of abdominal wall, unidentifiable UV fold of peritoneum, advanced bladder, bladder injury, wound infection and other similar difficulties have been mentioned in other studies also. ${ }^{11}$ Dense adhesions which also have been reported by other investigators not only create difficulties for the surgeon but may also pose an increased risk to the patient by prolonging operation time and by increasing the risk of injury of adjacent organs. ${ }^{12,13}$

\section{CONCLUSION}

In conclusion, with the growing rate of cesarean deliveries worldwide, women should be counselled that the repeat cesarean are bound with surgical difficulties and complications. If available, its imperative to take the senior obstetricians help for better surgical outcome. Anticipation of complications, early decision and active intervention reduces morbidity and prevent mortality as most of the women report for admissions late in labour.

Funding: No funding sources

Conflict of interest: None declared

Ethical approval: The study was approved by the Institutional Ethics Committee

\section{REFERENCES}

1. Kwawukwume EY. Caesarean section. Kwawukwume EY, Emuveyan EE (Editors). In: Comprehensive obstetrics in the tropics Damsona, Ashante and Hittscher; 2002:321-9.

2. Ainbinder WS. Caesarean section. Decherney AH, Nathan L (Editors). In: Current obstetric and gynaecologic th diagnosis and treatment. $9^{\text {th }}$ ed. McGraw Hill Publishers; 2003:518-30.
3. Johnson DD. Caesarean Delivery. Gilstrip III CL, Cunningham GF, Vandorstrom JP (Editors). In: Operative nd obstetrics. 2 Edition; McGraw Hill Publishers. 2002:257-73.

4. Nkwo OP, Onah EH. Feasibility of reducing caesarean section rate at the University Teaching Hospital, Enugu, Nigeria. Trop J Obstet Gynaecol. 2002;19(2):86-9.

5. Ezechi OC, Fasuba OB, Dare FO. Socioeconomic barriers to safe motherhood among booked patients in rural Nigerian communities. J Obstet Gynaecol. 2000;20:32-4.

6. Ojo VA, Okwerekwu FO. A critical analysis of the rates and indication for caesarean section in a developing country. Asia-Oceanic. J Obstet Gynaecol. 1988;14:185-93.

7. Myus SA, Bennett TC. Incidence of significant adhesions of repeat cesarean section and the relationship to method of prior peritoneal closure. $\mathrm{J}$ Reprod Med. 2005;50:659-62.

8. Garba NA, Mohammed Z. Caesarean Morbidity and Mortality at Aminu Kano Teaching hospital Kano: A two-year review. BOMJ. 2016;8(1):10-14

9. Curtin SC, Gregory KD, Korst LM, Uddin SF. Maternal morbidity for vaginal and cesarean deliveries, according to previous cesarean history: new data from the birth certificate, 2013. National vital statistics reports: from the Centers for Disease Control and Prevention, National Center for Health Statistics, National Vital Statistics System. 2015 May 20;64(4):1.

10. Munshi SP, Munsho KS, Mehta AR, Solanki SB. Maternal complications during caesarean section: study of 50 cases. Indian J App Res. 2015;5(12):612 .

11. Kumar VCR, Hinder P. Study of surgical difficulties encountered in repeat cesarean sections in comparison with the primary cesarean section. IOSR J Dent Med Sci. 2016;15(1):88-91.

12. Ramkrishnarao MA, Popat GH, Eknath BP, Panditrao SA. Intra-operative difficulties in repeat cesarean section: a study of 287cases. J Obstet Gynecol India. 2008;58:507-10.

13. Victoria N, Shlomi B, Barnett GO. Maternal complications associated with multiple cesarean deliveries. Obstet Gynecol. 108(1):21-6.

Cite this article as: Sheela WG, Chellatamizh M, Mohanambal M. Critical analysis of surgical difficulties and postoperative morbidities of caesarean deliveries: a rural teaching hospital experiences in silk city, South India. Int J Reprod Contracept Obstet Gynecol 2017;6:2565-8. 